Tackling Causes and Consequences of Health Inequalities: A Practical Guide James Matheson, John Patterson, and Laura Neilson

CRC Taylor \& Francis Group Ltd, 2020, PB, 364pp, E27.99, 978-1138499867

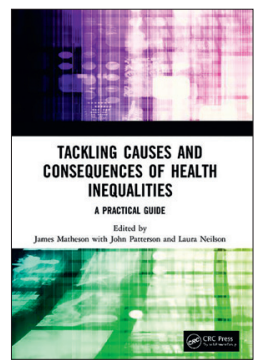

\section{SOCIAL DISADVANTAGE}

This book addresses a key ongoing cause of ill health, which as a GP impacts on my daily work at all levels - but is often implicit, and feels hard to address in any effective way.

I went into general practice because I liked the idea of prevention, and being upstream of preventable damage. Forty years on, at the end of a period in the UK of disinvestment in public services and an emphasis on competitive markets, I continue to see many patients whose life chances and health are chronically disadvantaged by social rather than biological factors. And I have come to understand that many of the adverse personal choices made by some of the people I meet are also attributable to forces bigger than themselves.

This book is a book I wish I could have read at the start of my career because it takes the analysis up and out beyond the individual patient and their environment, into common factors and ways of analysing and understanding risk. It is a multilayered book that looks at different populations, manifestations of inequality and clinical and educational interventions. It crosses between very personal accounts and examples of good practice to highly analytical sections and summaries of the relevant evidence. The main sections look at theoretical and experiential perspectives, relevant knowledge and necessary skills, the needs of specific patient groups, and finally into the implications for education and learning approaches.

Each of the 30 chapters is separately authored - and while this leads to a degree of conceptual repetition, it ensures a rich and varied read, all of which is deeply professional and insightful. For me, the most important focus was the argument that GPs need to act at the community/local level rather than focus on individual needs, or professional advocacy.
The UK general practice structure is only just beginning to move into genuine multisector working. Liaison with other agencies around specific client needs is not at all the same as working with charities, communities, and local authorities to support people in their non-medical needs. The new concept of 'social prescribing' is a convenient term for this kind of working. and this book makes the case for this approach - though many may feel it is a big ask to add new initiatives into an already challenging workload and workforce environment.

Fortunately, this book inspires and justifies - if you were sceptical before, the authors' passion for the need to reach out to those damaged through no fault of their own by the cards dealt to them by their social environment made me more determined than ever to try to address the health consequences of an inequitable society - and to find new and more appropriate ways to do this.

\section{Amanda Howe,}

President RCGP, Immediate Past President WONCA, Professor of Primary Care, Norwich Medical School, UEA, Norwich

\section{Email: Amanda.HoweArcgp.org.uk}

DOI: https://doi.org/10.3399/bjgp20X710645

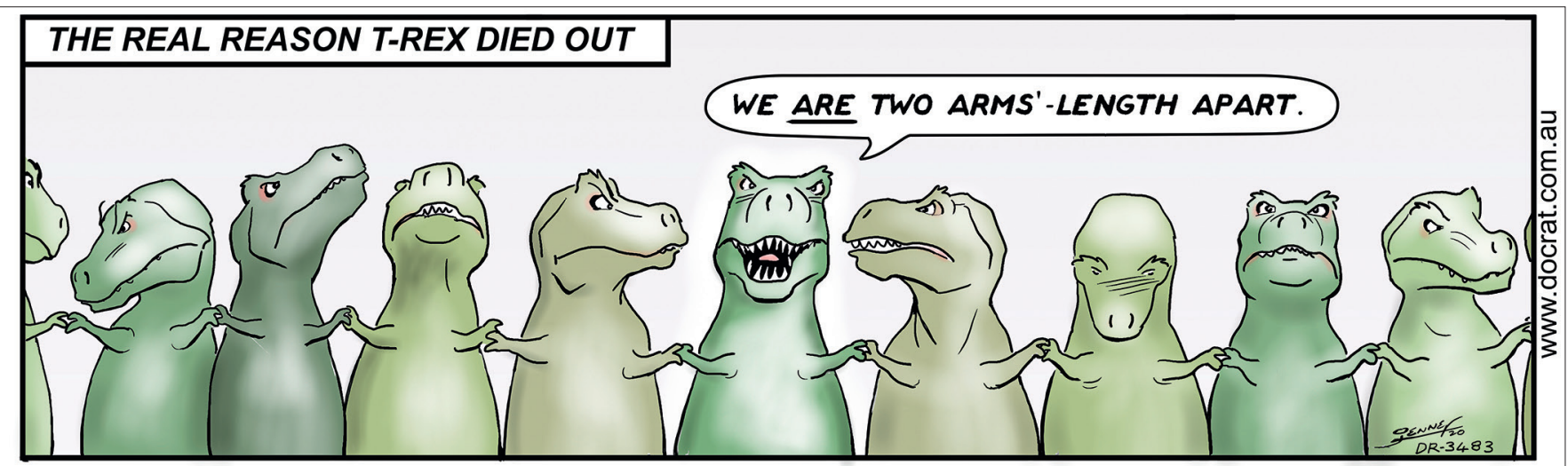

